\title{
Assessing the land cover situation in Surkhang, Upper Mustang, Nepal, using an ASTER image
}

\author{
Benktesh D Sharma†*, J an Clevers $\$$, Reitze De Graaf̧ and Nawa R ChapagainףI \\ $\dagger$ King Mahendra Trust for NatureConservation, Kathmandu, Nepal \\ \$ Laboratory of Geo-Information and RemoteSensing,Wageningen University, TheNetherlands \\ $\S$ Forest Ecologyand Forest Management Group, Wageningen University, TheNetherlands \\ II King Mahendra Trust for NatureConservation, Kathmandu, Nepal \\ *Towhom correspondenceshould beaddressed.E-mail: bdsharma@kmtnc-acap.org.np
}

\begin{abstract}
This paper describes the remote sensing technique used to prepare a land cover map of Surkhang, Upper Mustang Nepal. The latest ASTER image (October 2002) and an ASTER DEM were used for the land cover classification. The study was carried out in Surkhang Village Development Committee (area $799 \mathrm{~km}^{2}$ ) of Upper Mustang region. The study area falls within the Annapurna Conservation Area. Field surveys for training data, ground truthing and spectral signature collection were carried out during May-J une 2002. Various image classification algorithms were tested, and the one that yielded the best result was used for image classification. The land cover situations with their aerial extents were identified and topographic analysis was carried out to study the variations of different land covers types in the region. Various species of grasses covered about $36 \%$; shrubs covered about 32\%; bare land, which includes area from completely bare to less than $10 \%$ vegetation, constituted about $20 \%$ of the land resources of the study area. Grassland was found abundant in eastto south-facing slopes, while shrub species were abundant in flat regions and west- to north-facing slopes.
\end{abstract}

Key words: ASTER image, DEM, land cover mapping, Mustang, Nepal, GIS, remote sensing

Him J Sci 1(2): 93-98

URL: www.himjsci.com/issue2/landcover
Received: 26 Apr 2003

Accepted after revision: 12 June 2003

\section{Introduction}

Land cover mapsrecord thestructureand make-up of alandscape. A map structure related directly to real features on the ground can help to understand and interpret the environment. It shows the inter-connectivity of landscape features, their immediate context and the wider neighborhood in which environmental influences operate. This type of map helps to see how ecological principles can explain patterns of landscape diversity.

Recent improvements in satellite image quality and availability havemadeit possibleto perform imageanalysisatmuch larger scale than in the past. This will likely lead to a wider use of satellite imagery at the regional level as a reliable source of timely and accuratespatial data. In recent years, Geographic Information System (GIS) technologies have greatly increased ability to map and model land cover, providing resource managers and researchers with a tool to analyze data and address specific problems at a variety of spatial scales, in less time, and in a more cost-effective manner (Ramsey et al. 1999).

Land cover classification involves grouping of componentsinto homogeneousunitson thebasis of characteristics significant to themanagement of land resources. Through remote sensing techniques supplemented with field surveys, an accurate land cover map can be prepared in cost effective manner than manual survey land cover mapping, and both biotic and abiotic surface features, including vegetation composition and/or density and local landforms, can beinterpreted (Best 1984).

The changing land cover conditions can be quantified usingchangedetection remotesensingtechniques. Remotesensing techniques, together with ground truth data, are widely used to collect information on the qualitative and quantitative status of natural resources in protected areas. With the advent of satellite technologyand GIS, ithasbeen now well-accepted toolsto establish and model spatial information (Mongkolsawat and Thirangoon 1998).

Satellite imagery interpretation is one way of obtaining information on land use resources that has also been emphasized in the Management Information Systems (MIS) plan of the Annapurna Conservation Area Project (ACAP) (Chapagain 2001). Once these resources are assessed and integrated with other biophysical and socio-economic information of management relevance, land cover mapping being an activity for resource assessment, theMIS would support decision making in theproject area. Thisstudy was carried out with theobjective of assessing land resources in the Upper MustangBiodiversity Conservation Project (UMBCP) of King Mahendra Trust for Nature Conservation (KMTNC) and preparing an accurate and up-to-date land cover map of Surkhang, Upper Mustang.

\section{Materials and methods}

Study area

The study was carried out in Surkhang, the largest of the seven Village Development Committees (VDCs) in Upper Mustang (In Nepal theVDC isthesmallest administrativeunit.)Thegeographic coverage ranges approximately from $28^{\circ} 50^{\prime} 19^{\prime \prime}-29^{\circ} 09^{\prime} 10^{\prime \prime} \mathrm{N}$ and $83^{\circ} 49^{\prime} 41^{\prime \prime}-84^{\circ} 15^{\prime} 16^{\prime \prime} \mathrm{E}$. The land cover classification and mapping for this VDC was carried out over an area of about $784 \mathrm{~km}^{2}$; the remaining $15 \mathrm{~km}^{2}$ was not included in this research due to unavailability of satellite data. This VDC borders on Tibet in the east, and is one of the most remote areas of Nepal (Plate 1).

Theregion issituated in theHimalayan rain shadow and 


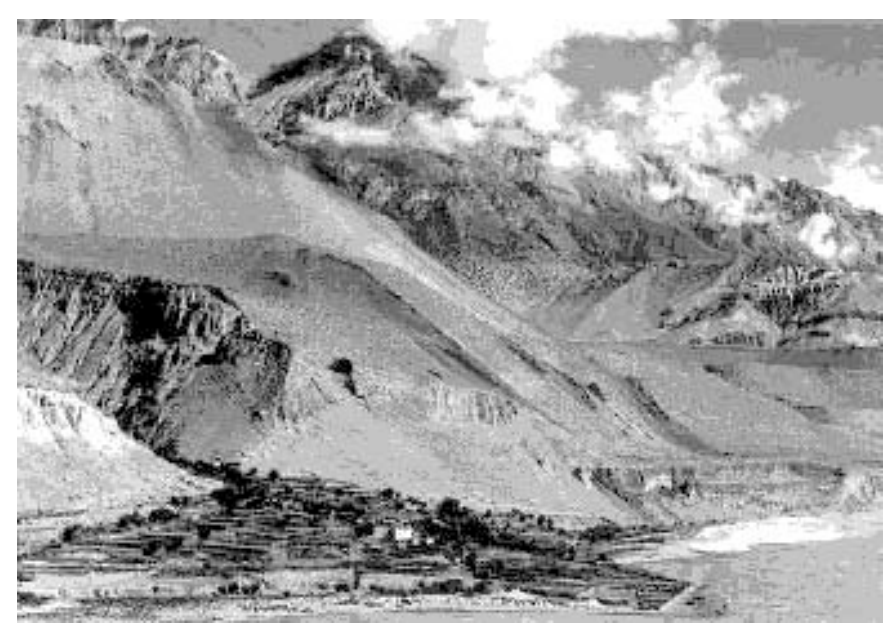

PLATE 1. A landscape view of Upper Mustang

receives less than $100 \mathrm{~mm}$ rainfall annually (HMGN 1999). More than 40 percent of Mustang's area is rangeland and pasture at altitudes of 3,000 to higher than 5,000 $\mathrm{m}$ asl (Blamont 1996); the elevation of our study area ranges from 3000 to more than $6000 \mathrm{~m}$ asl. The wholeVDC remains under snow for $4-5$ months (November to March). The Upper Mustang region is said to be the southern extension of the Tibetan plateau. The climate and landscape of Upper Mustang are similar to that of Tibetan plateau. Alluvial fans, jutting sandstone ridges, abandoned glacial moraines and broad sandy terraces are among the more conspicuous elements of this highly accidented landscape. Mean annual daytime temperatures are around $21^{\circ} \mathrm{C}$, but mean annual nighttime temperatures may fall to $5^{\circ} \mathrm{C}$. Only herders and pastoralists visit the northern area of this VDC, often for 2-3 months in summer (Figure 1).

\section{Remote sensing data}

A surface radiance image of Advanced Spaceborne Thermal Emission and Reflection Radiometer (ASTER) taken on October 2002 and ASTER Digital Elevation Model (DEM) (ASTER 2001) were used for the land cover classification. ASTER covers a wide spectral region with 14 bands from visible to thermal infrared with high spatial, spectral and radiometric resolution. An additional backwardlooking near-infrared band provides stereo coverage (Abrams and Hook 2001), which is generally used for the preparation of DEM. The spatial resolution varies with wavelength: $15 \mathrm{~m}$ in the visible and near-infrared (VNIR) region, $30 \mathrm{~m}$ in the short wave infrared (SWIR) region, and $90 \mathrm{~m}$ in the thermal infrared (TIR) region. This ASTER image was geo-referenced with the help of topographic maps of the study areas by locating 18 conspicuousground control points (GCPs), such as ridges and confluences. For the sake of computational simplicity, a first order polynomial transformation with the nearest neighbour resampling technique was used (Lillesand and Kiefer 2000); this entailed directly assigning the digital number (DN) in the input file that overlaps the pixel in the output file, avoiding the necessity of altering the original input pixel values (Richards 1993). For the analysis a spatial resolution of $30 \mathrm{~m}$ was used. The root mean square error was 0.21 pixels.

Although the original ASTER image had 14 bands, for this study only nine bands covering visible to short wave infrared were used. The thermal bands were not used because of their coarse resolution $(90 \mathrm{~m})$.

The image acquisition date was in winter when the cultivated fields of Upper Mustang were devoid of crops. The roofs of houses in UM regions are made mostly of mud. The agricultural fields are found in the surrounding of houses. The field survey phase identified that in winter the vegetation cover on agricultural fields was limited to grasses and shrubs, and many were completely barren. Such fields were not correctly distinguished as a separate class in satellite images. Therefore, cultivated areas were digitized from topographic maps. Eleven such agricultural areas were identified on the available topographic maps. These fields were masked in the original image and excluded from classification. For statistical estimates and map preparation, these areas were reincorporated into the classified image.

Principal components analysis (PCA) allows compaction of redundant data into fewer bands thereby reducing the dimensionality. The bands of PCA data are noncorrelated and independent, and are often more interpretable than the source data, yielding better classification results (ERDAS Inc 1999). Nine principal components were derived from the original 9 bands of the ASTER. The information contained in each component was checked and the components containing most information were used for the analysis.

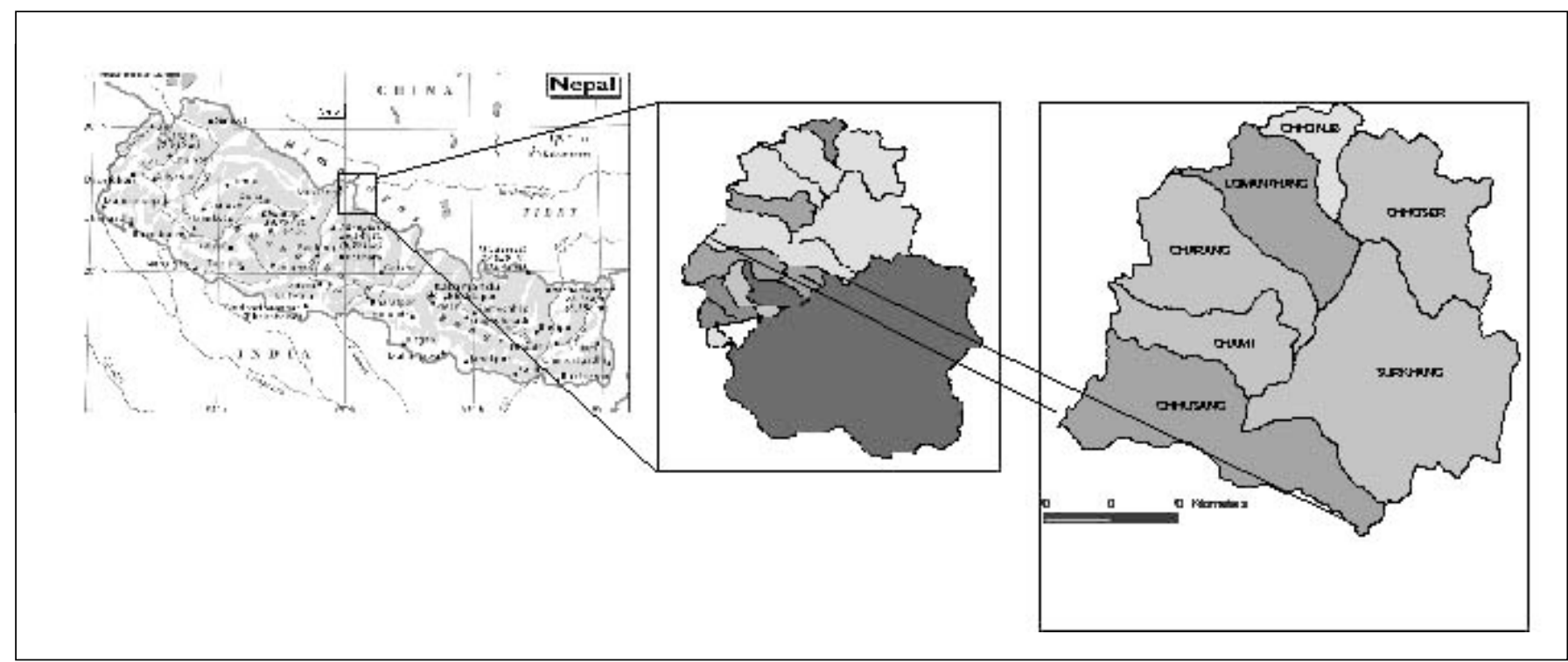

FIGURE 1. Map of the study area: Nepal (left), Annapurna conservation area showing the different VDCs of Mustang (middle) and Upper Mustang showing Surkhang, the study area (right) 
BOX 1. Description of land cover classes used to classify the study area

\begin{tabular}{|c|c|}
\hline Coverclass & Description \\
\hline $\begin{array}{l}\text { Agriculture } \\
\text { and settlement }\end{array}$ & $\begin{array}{l}\text { This class includes villages and community settlements, as well as adjoining crop fieldsand treestands. Usually } \\
\text { trees and crop fields arealong the periphery of clustered houses. Almost all of thisclass liesalong riverbanks. Thisis } \\
\text { the pattern of settlement throughout theUpper M ustang region. }\end{array}$ \\
\hline Bareland & $\begin{array}{l}\text { Thisclassincludes the land surface with little or no cover (i.e. less than } 10 \% \text { vegetation cover). The region of rock- } \\
\text { falls is also included in this class. }\end{array}$ \\
\hline Water bodies & $\begin{array}{l}\text { Rivers, streams, and rivulets constitute this class. Lakes formed by glaciers are frequently found above } 5000 \mathrm{~m} \\
\text { elevation. Perennial rivers, glacial lakesand permanent water bodies areincluded in thisclass whilethesmall rivers } \\
\text { which remained dry during thetimeof image acquisition are not included }\end{array}$ \\
\hline Grassland & $\begin{array}{l}\text { This is the most prevalent land cover of the area, usually above } 4000 \mathrm{~m} \text {. All high altitude pastures with smooth } \\
\text { slopes consist of alpinegrasses. The habitat is highly favored by blue sheep and other grazers. }\end{array}$ \\
\hline Shrubland & $\begin{array}{l}\text { Thisisthe second most prevalent land cover class above } 3000 \mathrm{~m} \text {. Lonicera obovata and Caragana spp. dominatethis } \\
\text { class, associated in some locales with Berberisspp. }\end{array}$ \\
\hline Snowcover & This class includes those peaks with permanent snow cover. They are usually found above $6000 \mathrm{~m}$ elevation. \\
\hline
\end{tabular}

The normalized difference vegetation index (NDVI) is calculated from the reflected solar radiation in the near-infrared (NIR) and red (RED) wavelength bands via the algorithm.

The NDVI is a nonlinear function, which varies between -1 and +1 but is undefined when RED and NIR are both zero. The NDVI can beused as an indicator for theamount of green biomass. It is used to discriminate vegetated and non-vegetated regions in imageanalysis to improveclassification results.

Aspect in general has greater significance in vegetation characteristics as it determines the amount of radiation available for the plant. Around the world, aspect and slope are used as predictors of vegetation types (Hamilton et al. 1997). The aspect and slope images were derived from the available DEM and used to test if they contributesignificantly in cover typediscrimination.

A review of studies carried out by Koirala and Shrestha (1997) and Raut (2001) wereundertaken in order to obtain ageneral picture of land cover classes of theregion. Takinginto consideration theseearlier studiesas well as thefeasibility of cover discrimination by image analysis, we developed a classification scheme (Box 1).

An unsupervised classification, the iterative selforganizing data analysis (ISODATA) clustering algorithm, which operates by initially seeding a specified number of cluster centroids in spectral feature space (Debinski et al. 1999), was used to get an idea of possible cover classes of the region. It served as an aid for the supervised classification and selection of appropriate sites duringthetrainingstage.

Supervised classification isan essential tool for extracting quantitative information from remotely sensed image data (Richards 1993). For this technique, a number of mathematical approaches have been developed (Lillesand and Kiefer 2000). We tested four common al gorithmson thefirst 3 bands (in VNIR region) of the ASTER image: minimum distance to mean (MDM), mahalanobisdistance(MHD), parallelepiped (PPL) and maximum likelihood (MLH). The algorithm that gave best results in terms of accuracy was chosen for the final classification.

Training data were collected in order to obtain good representatives of each vegetation type(Lillesand and Kiefer 2000). Field observations, aerial photographs, topographical maps, Global PositioningSystem (GPS) survey and theimage of theunsupervised classification were used to collect data from 70 trainingsites, which included all types of land cover designated for the work. Spectral signatures were collected from a wide range of elevations (3000 to $5600 \mathrm{~m}$ asl). Signatures were also collected from sites with differences in topographic slope and aspect in order to normalize differences in radiance. Two sets of data, one for the classification and another for theevaluation of theclassified image, werecollected. Thecollected spectral signatureswereevaluated by plotting the mean spectral signature and checking if the classes could be discriminated using the given set of bands in the image. We also plotted thesignatureellipsesin thefeaturespace. Thespectral mean plot was calculated for a composite of 17 bands: 9 original ASTER bands, 4PC bands, DEM, slope, aspectand NDVI image. Thishelped to determine which bands to includefor theclassification.

\section{Results and discussion}

Results of principal component analysis

PC 1 contained $80 \%$ of the information of the 9 original ASTER bands. The combination of 4 principal components constituted more than $99 \%$ of theinformation (Table1). This means that 4PCs can give $99.89 \%$ of the information that the 9 original bands could do. Therefore these 4 bands were used to determine the optimum band combination for land cover classification.

Obtaining an optimum number of land cover classes

The results of the classified image of the unsupervised (ISODATA) classification were used to create a histogram. The result of the histogram is presented in the form of a line graph of the classes (Figure 2). If a sharp decrease is present in the histogram, it could represent thepoint whereadditional clustersareirrelevant(Tatham and O'Brien 2001). Sincethereisa sharp fall in thenumber of pixels

TABLE 1. Principle components (PC) and \% information contained

\begin{tabular}{lll}
\hline PC & \%explained variance & Cumulative\% \\
\hline 1 & 80.66 & 80.66 \\
\hline 2 & 18.57 & 99.23 \\
\hline 3 & 0.55 & 99.77 \\
\hline 4 & 0.11 & 99.89 \\
\hline 6 & 0.06 & 99.95 \\
\hline 7 & 0.02 & 99.97 \\
\hline 8 & 0.02 & 99.99 \\
\hline 9 & 0.01 & 99.99 \\
\hline
\end{tabular}




\section{RESEARCH PAPERS}

after the seventh class, it is concluded that seven classes would be sufficient. However, during the field survey and ground truthing workit wasfound appropriateto makea land cover map comprising only 6 classes (as per the management relevance of the scope of this work) (Box 1).

Spectral signature evaluation

The spectral signatures of five classes (excluding agriculture and

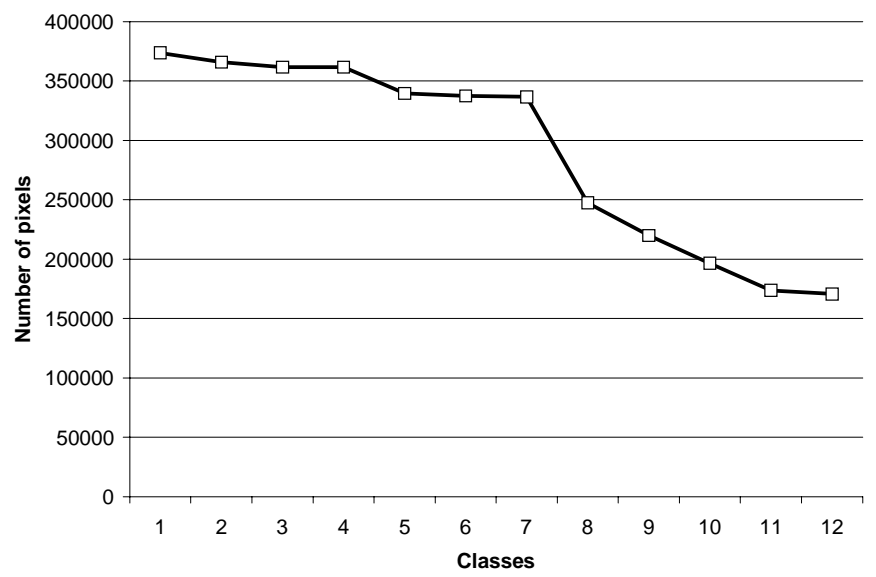

FIGURE 2. Line graph of histogram analysis of 12 clusters (results of ISODATA unsupervised classification) settlements) were plotted against the 17 bands to evaluate and determine which band combinations could best discriminate the cover classes (Figure3). Bands 3, 5, 7,8and 9 could easilydiscriminate the classes. PC 1 can discriminate the classes as well. Aspect and NDVI image could discriminate the vegetated classes from the non-vegetated ones. The PC 1 image, which contains only $88.66 \%$ of the information of the original 9 bands, could differentiate the cover classes better than original 1,2,4, and 6 bands. Wetested our hypothesisthat theinclusion of thisPC 1 image could compensate for the loss of information of the excluded bands 1, 2, 4 and 6. A combination including PC 1 and another combination withoutPC 1 were compared to find out if this hypothesis was valid.

UseofDEM asa separateband did notgive usable results. In the spectral plot, the DEM could discriminate the classes, but that is notmeaningful as the valuesarethelocations of the pixel for which theclassesweretaken. Eiumnoh and Shrestha(1997) reported that DEM enhanced the classification techniques in their studies. An unsupervised classification was run in the original bands with DEM and the result was not as expected. Rather, the inclusion of DEM asa separateband resulted in arough classification of elevation zones in the image.

\section{Selection of appropriate classifier}

The results of supervised classification carried out over the three bands (in VNIR region to test the classification algorithms) using four different classification algorithms (Table 2). These accuracy assessments were done by using an independent set of ground datai.e., other than that used for classification.

Amongthese 4tested classifiers, themaximumlikelihood classifier gave superior results in terms of accuracy. Therefore, this

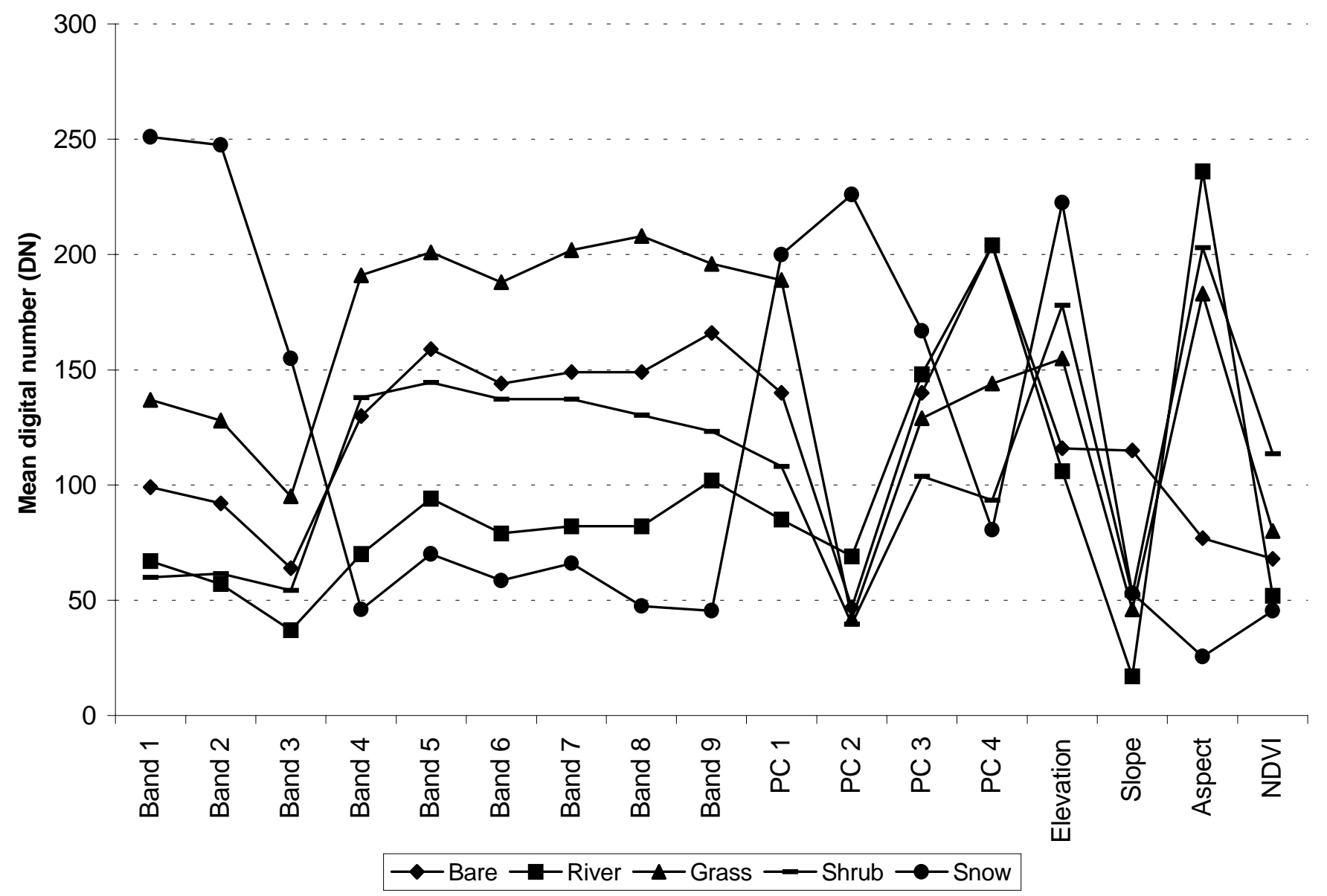

FIGURE 3. Spectral signatures mean plot of the classes 
classifier was used for all subsequent studies including the final classification.

Selection of appropriate band combinations for classification Detailed analysis of the available spectral and DEM information showed that 4 combinations were promising for discriminating the six classes (Sharma 2003). To find out the most suitable bands for classification, these combinations were classified using maximum likelihood classifier with a $95 \%$ confidenceinterval. The results in terms of classification accuracy for the bands tested are given in Table 3.

Since the classification of BC 4 which constituted bands $3,5,6,7,8,9$, NDVI and aspect gave the best overall classification accuracy, this combination was used for final classification. The users' and producers' accuracy are given in Table 4. It was found that theinclusion of PC bandswhen other original bandssufficeto discriminatetheclasses did notenhancetheclassification accuracy. A 3 by 3 majority filter was applied in order to smoothen the salt-and-pepper appearance in the classified image according to themethodsand rational described byEastman (1997). Theland cover map and its information are presented in Figure4and Table 5 respectively.

Vegetation patterns and their characteristics in Upper Mustang Thespatial analysiscarried outusing GISshowed that theagriculture and settlement class was found between 3036 and $4212 \mathrm{~m}$ asl. Cultivated fields and settlements were scattered and constitute only a small portion of thetotal land cover in the region. Snow was observed atelevationsas low as $5172 \mathrm{~m}$ asl. Grasslandswerefound up to $7101 \mathrm{~m}$ asl, while shrub lands were found up to $7166 \mathrm{~m}$ asl. (Interpretation of the values related to elevation should take into account the release notes of DEM given in ASTER 2001).

In the study of the general distribution of vegetation in thestudy area by aspect, grass species which were generally more light-demanding werefound primarily on east- to southwest-facing slopes, while shrub species, which are shade tolerant, were found on coolernorth-, west-, and northwest-facingslopes, which received fewer hours of sunlight (Figure 5).

TheNDVI analysisshowed that theshrub landshad higher biomass (NDVI values) than grasslands. The NDVI, which varies between -1 and +1 in general, was found to bebetween -0.46 to 0.32 for shrub land and -0.34 to 0.23 for grassland. The NDVI image within each of the grassland and shrub land was classified into 3 classes to represent low, moderate and high density. The results showed that the study area contained, for the most part, a low density of grasslands and a moderate density of shrub land (Table 6).

\section{Conclusions}

A classification of land cover with a high level of accuracy was obtained from an ASTER image with maximum likelihood classifier. Inclusion of ancillary datasuch as NDVI and aspectimagesincreased the classification accuracy. Based on the October 2002 image, we found that cultivated land and settlements cover $0.31 \%$, bare land $20.19 \%$, water bodies $1.82 \%$, grassland $36.01 \%$, shrub land $32.57 \%$ and snow $9.11 \%$ of the total area of Surkhang. Grass species were abundant in east- to south-facing slopes while shrub species were abundant in flat and west- to northwest-facing slopes. The vegetation analysisshowed that Surkhang containsa low density of

TABLE 2. Classification accuracy of different classifiers

\begin{tabular}{lll}
\hline SN & Classification algorithm & Overall accuracy \\
\hline 1 & Minimum distanceto mean (MDM) & $64.38 \%$ \\
2 & Mahalanobisdistance(MHD) & $66.93 \%$ \\
3 & Parallelepiped (PPL) & $62.03 \%$ \\
4 & Maximumlikelihood(MLH) & $67.44 \%$ \\
\hline
\end{tabular}

TABLE 3. Description of band combinations $(B C)$ and the accuracy obtained

\begin{tabular}{llr}
\hline $\begin{array}{l}\text { Band } \\
\text { combination }\end{array}$ & $\begin{array}{l}\text { Constituent } \\
\text { bands }\end{array}$ & $\begin{array}{r}\text { Overall } \\
\text { accuracy }\end{array}$ \\
\hline 1 & Bands 1, 2, 3, 4, 5, 6, 7, 8, 9 & $77.78 \%$ \\
2 & Bands 1,2,3, 4, 5, 6, 7, 8, 9 and Aspect & $79.07 \%$ \\
3 & Bands 3, 5, 7, 8, 9, PC1, NDVI and Aspect $91.73 \%$ \\
4 & Bands 3, 5, 7, 8, 9, NDVI and Aspect & $92.25 \%$ \\
\hline
\end{tabular}

TABLE 5. Area of land cover classes

\begin{tabular}{lll}
\hline Class & Percent & Area $\left(\mathbf{k m}^{\mathbf{2}}\right)$ \\
\hline Agricultureand settlements & 0.31 & 2.44 \\
Bareland & 20.19 & 158.31 \\
Water body & 1.82 & 14.25 \\
Grassland & 36.01 & 282.34 \\
Shrub land & 32.57 & 255.38 \\
Snow cover & 9.11 & 71.40 \\
\hline Total & 100.00 & 784.11 \\
\hline
\end{tabular}

TABLE 6. NDVI characteristics of two vegetation types

\begin{tabular}{llllll}
\hline \multirow{2}{*}{ Category } & \multicolumn{2}{c}{ Grassland } & & \multicolumn{2}{c}{ Shrubland } \\
\cline { 2 - 3 } \cline { 5 - 6 } \cline { 5 - 6 } & NDV & NDV & & ND & $\%$ \\
\hline Low & -0.345 to -0.152 & 68.36 & & -0.462 to -0.20 & 4.78 \\
Moderate & -0.152 to 0.041 & 31.62 & & -0.20 to 0.062 & 91.67 \\
High & 0.041 to 0.234 & 0.01 & & 0.062 to 0.324 & 3.55 \\
\hline
\end{tabular}

TABLE 4. Producers' and users' accuracy of classified image using BC 4

\begin{tabular}{llllll}
\hline $\begin{array}{l}\text { Class } \\
\text { name }\end{array}$ & $\begin{array}{l}\text { Reference } \\
\text { total }\end{array}$ & $\begin{array}{l}\text { Classified } \\
\text { total }\end{array}$ & $\begin{array}{l}\text { Number } \\
\text { correct }\end{array}$ & $\begin{array}{l}\text { Producers } \\
\text { accuracy }\end{array}$ & $\begin{array}{l}\text { User's } \\
\text { accuracy }\end{array}$ \\
\hline Bareland & 104 & 102 & 97 & $93.27 \%$ & $95.10 \%$ \\
\hline Water bodies & 30 & 32 & 28 & $93.33 \%$ & $87.50 \%$ \\
\hline Grassland & 99 & 118 & 97 & $97.98 \%$ & $82.20 \%$ \\
\hline Shrub land & 92 & 73 & 73 & $79.35 \%$ & $100.00 \%$ \\
\hline Snow cover & 62 & 62 & 62 & $100.00 \%$ & $100.00 \%$ \\
\hline Totals & 387 & 387 & 357 & & \\
\hline
\end{tabular}



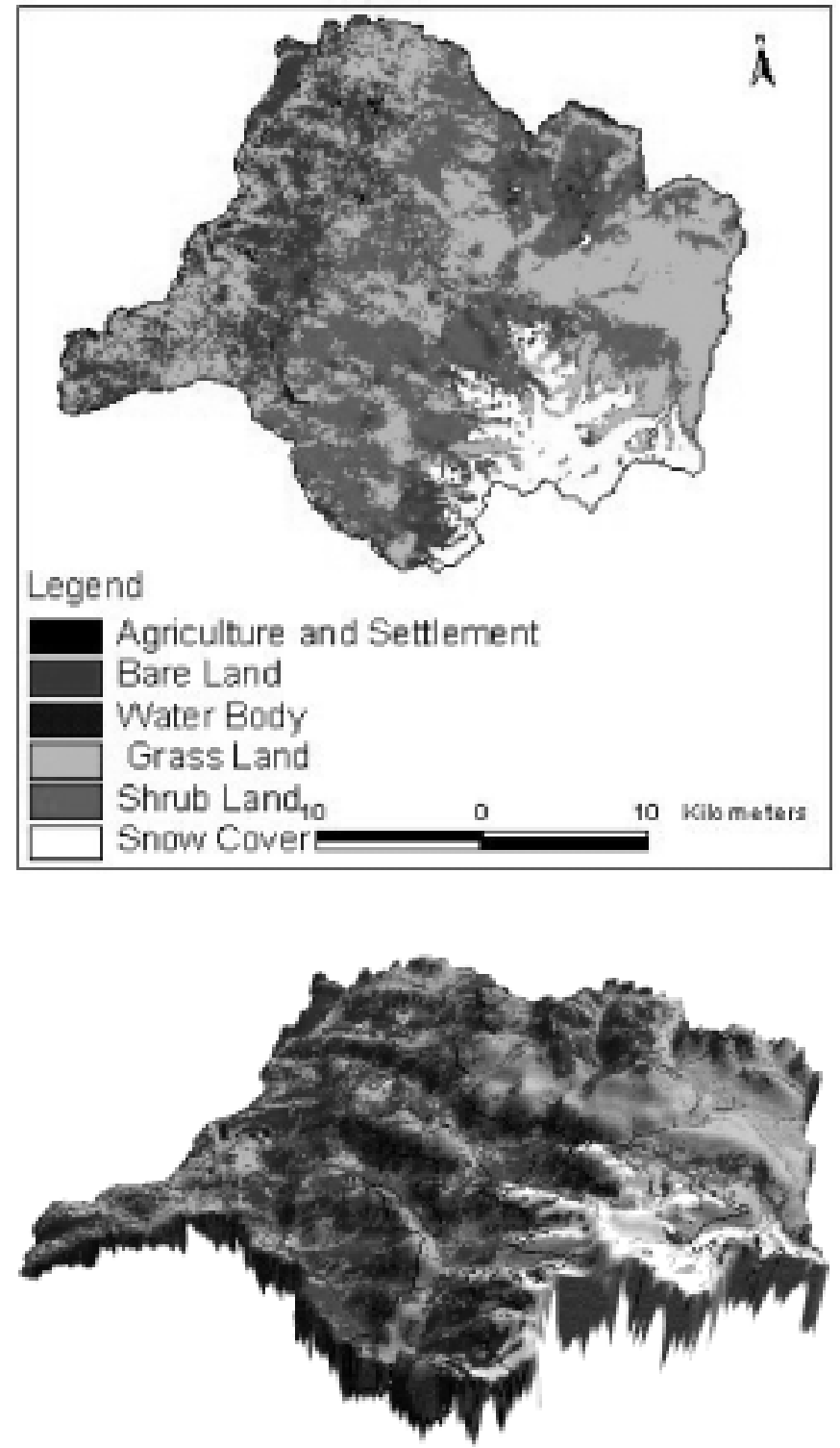

FIGURE 4. Land cover map of Surkhang (upper) and a 3 dimensional perspective view created by draping the land cover map over the Digital Elevation Model of the of the same study area (lower)

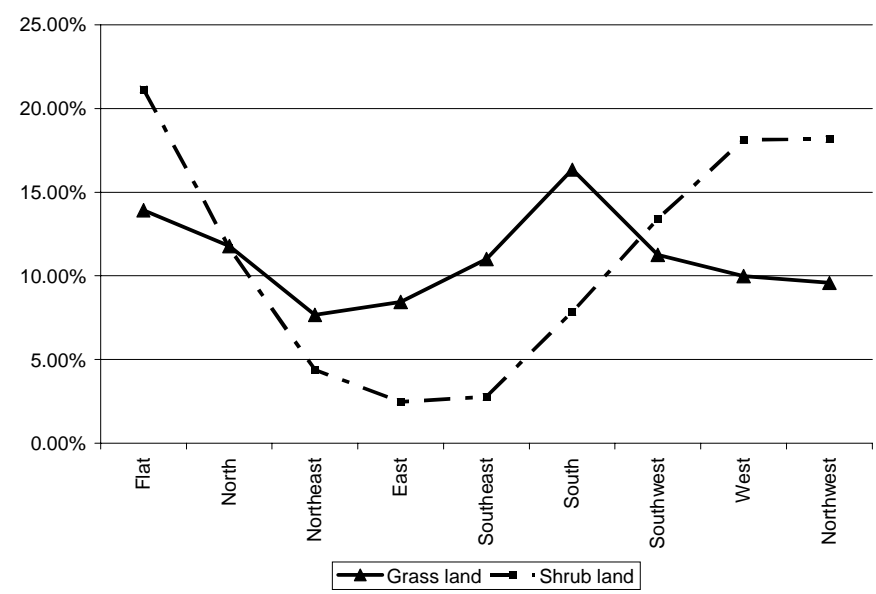

FIGURE 5. The distribution of vegetation at different aspects grass species and a moderate density of shrub species. The output of thisstudyisthe data regardingland cover and spatial relationships, which may contribute to any spatial analysis related to the study area for the Management Information Systems.

\section{References}

Abrams M and SHook. 2001. ASTER user'shandbook, Version 2. Pasadena (CA): Jet Propulsion Laboratory. 135p

ASTER. 2001. ASTER DEM release notes: ASTER digital elevation model AST14DEM-relative, Version 2.00. In: ASTER higher level productsuser guide Pasadena (CA): Jet Propulsion Laboratory. p 27-8

Best R. 1984. Remotesensing approaches for wild lifemanagement. In: Renewable resourcemanagement: Application of remotesensing. Proceedings of theRNRF Symposium on theapplication of remotesensingto resourcemanagement: 1983 May 22-27; Seattle (WA). p 55-96

BlamontD. 1996. Upper Mustang'sshiftinganimal husbandrypracticesin rangelands and pastoral development in theHindu Kush-Himalayas. Proceedings of a regional experts' meeting; 1996 Nov 5-7: Kathmandu, Nepal

Chapagain NR. 2001. GIS based management information system for Annapurna Conservation Area, Nepal. http://www.gisdevelopment.net/application/ $\mathrm{nrm} /$ mountain/mount0005.htm

Debinski DM, K Kindscher and ME Jakubaskas. 1999. A remote sensing and GIS based model of habitats and biodiversity in theGreaterYellostoneEcosystem. Int J RemoteSensing 20(17): 3281-91

Eastman JR. 1997. IDRISI for windows: User's guide, Version 2.0. Worcester (MA): Clark University

Eiumnoh A and RP Shrestha. 1997. Can DEM enhance the digital image classification?In: Proceeding of the18th Asian Conferenceon remotesensing (ACRS); 1997 Oct 20-24; Malaysia. Asian Association on Remote Sensing (AARS). http:// www.gisdevelopment.net/ aars/acrs/ 1997/ ts9/ ts9007pf.htm ERDASInc. 1999. ERDASfield guide, 5th ed. Atlanta. $698 \mathrm{p}$

Hamilton LS, DA Gilmour and DS Cassels. 1997. Montane forests and forestry. In: Mountains of theWorld: A gl obal priority. NewYork: Parthenon. p 281-311

HMGN. 1999. Daily precipitation records of Bheri, Rapti and Dhaulagiri zonethrough 1996. Kathmandu: Department of Hydrology and Meteorology, HMGN

Kazuhiro N, BK Baniya, SR Upadhyay, M Minani and AUjihara. 1995. Buckwheat cultivation and its utilization in U pper Mustang, Nepal. http:// soba.shinshuu.ac.jp/ contents/ 102.htm

Koirala RA and R Shrestha. 1997. Floristic composition of summer habitat and dietary relationships between Tibetan argali (Ovisammon hodgsonii), naur (Pseudoisnayaur) and domestic goat (Capra hircus) in theDamodar Kunda region of U pper Mustang in Nepal Himalaya[thesis]. Agricultural University of Norway

LillesandTM and RW Kiefer. 2000. Remotesensingand imageinterpretation, 4th ed. New York: John Wiley and Sons. $724 \mathrm{p}$

Mongkolsawat C and P Thirangoon. 1998. Application of satelliteimagery and GIS to wildlife habitat suitability mapping. In: Proceeding of the 19th Asian Conferenceon RemoteSensing; 1998 Nov 16-20; Manila. Asian Association on RemoteSensing (AARS). http:// www.gisdevelopment.net/ aars/acrs/ 1998/ ts11/ts11008pf.htm

Ramsey RD, AT Black, E Edgley, and N Yorgason. 1999. Useof GISand remotesensing tomap potential Columbian sharp-tailed grousehabitat in southeastern I daho. Idaho: USDepartment of Interior Bureau of Land Management. 12p

RautY. 2001. Thestatus of rangel and resourcesin Upper Mustang. Upper Mustang Biodiversity Conservation Project/ Annapurna Conservation Area Project/ King Mahendra Trust for Nature Conservation (UMBCP/ACAP/KMTNC). Research report series $5.129 p$

Richards|A. 1993. Remotesensing digital imageprocessing: An introduction, 2nd ed. Berlin: Springer-Verlag. $340 \mathrm{p}$

Sharma BD. 2003. Land cover classification and Equuskiang habitat mappingin Surkhang Nepal [thesis]. Wageningen University and Research Center, The Netherlands

Tatham B and D O'Brien. 2001. Bringingraster GIStothedistrict of North Vancouver. District of North Vancouver (CA): GISDepartment. BCIT GISstudent project report. $70 p$

UNDP. 2000. Preserving biodiversity and culture in Upper Mustang, Nepal. In Newsfront. UNDP Communication Office. http:// www.undp.org/dpa/ frontpagearchive/ september00/19sept00

\section{Acknowledgements}

This paper is based partly on the first author's M.Sc. thesis, which wascarried out at Forest Ecology and Forest Management Group; and Laboratory of GeoInformation and RemoteSensing atWageningen University, the Netherlands. We are grateful to Karan Shah, Natural History Museum, TU, Frits Mohren and Harm Bartholomeus, Wageningen University, for reviewing the paper and for providing methodological and technical assistance. Manythanks to Kishor Shrestha, Hira KC, Kaji R Adhikari and Basu D Neupanefor their help during data collection. UMBCP of KMTNC provided logistic support during the fieldwork. 